\title{
Me van a bajar la plusvalía: análisis de los efectos desencadenados por la localización de un condominio social en barrio Matta Sur, Santiago de Chile
}

My house would be depreciated: effects analysis of social housing location in the barrio Matta Sur, Santiago de Chile

\author{
Historial del artículo \\ Recibido: \\ 27 de mayo de 2020 \\ Revisado \\ 03 de septiembre de 2020 \\ Aceptado:
}

30 de octubre de 2020

\section{Gricel María Labbé Céspedes ${ }^{\mathrm{a}}$ y Roberto Salas Cortez ${ }^{\mathrm{a}}$}

a goplaceit.com. Correo electrónico: glabbe@goplaceit.com

\section{Palabras clave}

Condominio de interés social, demanda residencial, mixtura social, oferta, precios.

\section{Keywords}

Condominium of social interest, prices, residential demand, social mixture, supply.

\section{Resumen}

La propuesta de un municipio chileno de localizar un proyecto de vivienda social en una de las comunas más acomodadas de Santiago en el año 2018 provocó que los residentes del lugar manifestaran su rechazo aduciendo una eventual baja en las plusvalías de sus propiedades. Frente a tal hecho, el presente artículo busca evidenciar los efectos inmobiliarios y económicos de la localización de un conjunto de viviendas de interés social en el barrio Matta Sur de la comuna de Santiago. La metodología utilizada es eminentemente cuantitativa, y corresponde a un análisis de datos de demanda y oferta inmobiliaria en series temporales. La información examinada responde al análisis de ofertas publicadas en portales inmobiliarios. Los principales hallazgos señalan que no es posible atribuir a la instalación de un condominio social un menor interés en el barrio por parte de futuros arrendatarios o compradores. Con respecto a los datos de oferta, los precios de las propiedades siguen en aumento a pesar de la existencia del condominio social. Estas conclusiones hacen referencia que la presencia de un condominio social tiene efectos principalmente simbólicos y sociales, que no repercuten en términos económicos.

\section{Abstract}

In the year 2018 a Chilean local government proposal to locate a social housing project in the wealthiest commune of Santiago caused a resident social unrest who argumented may also occur a depreciation of their houses. This article explores the effects in the property market of the location of a social housing in the commune of Santiago. The methodology used is quantitative and analyze property supply and demand data in time series. The information analyzed comes from property listings published by real estate websites. The main research findings do not show a minor tenant or buyer interest in the neighborhood attributable to the location of social housing. Regarding to the supply data the prices of the properties continue raising despite the new houses. The main conclusion of the research shows a symbolic and social effects that do not have an economic implication. 


\section{Introducción}

En materia de política de vivienda de interés social y durante los últimos años, diversos gobiernos chilenos buscaron evitar que se continuara con la formación de grandes aglomeraciones de vivienda social en terrenos mal localizados y con nula presencia institucional, que derivaron en graves problemas de segregación residencial. Entre estas, iniciativas legislativas como señalan Mora, Sabatini, Fulgueiras \& Innocenti (2014) "la prohibición de construir conjuntos de más de 300 viviendas sociales, luego rebajada a 150 unidades, no evitó que las empresas inmobiliarias operaran por etapas e hicieran crecer la segregación de gran escala" (p. 27-28).

En la misma línea, Vergara-Erices \& Garín Contreras (2016) señalan que;

(...) la promulgación de políticas de vivienda social, la que en su espíritu apuntaba a una integración social y por lo tanto a una disminución de los niveles de segregación, situación que en la práctica no aconteció debido a que los valores del suelo en las zonas centrales son prácticamente inalcanzables para los ingresos de la población de bajos ingresos y los subsidios aportados por el Estado (p.460).
Las iniciativas que se originaron desde el gobierno central tuvieron nulos efectos y la segregación residencial, lejos revertirse, se amplió hacia otros territorios.

A raíz de esto, durante el año 2018, la iniciativa de un municipio de localizar un proyecto de vivienda social en una de las comunas con mayores ingresos de Santiago de Chile revivió la discusión referente a la localización de conjuntos de interés social en barrios consolidados.

El patrón de localización de la vivienda económica, desde el período de la dictadura acaecida durante la década de los 80 , ha sido impulsado por políticas neoliberales que han promovido su desarrollo en la periferia de las ciudades chilenas. Lo anterior ha desencadenado efectos sociales, económicos y simbólicos no previstos (Hidalgo, 2002; Sabatini, Cáceres \& Cerda, 2001), los que prevalecen hasta hoy, debido a la intensificación del consumo del suelo para densificación por parte de desarrolladores privados (López-Morales, 2013). Así, los nuevos conjuntos de vivienda social se han emplazado fuera de la mancha urbana de Santiago (figura 1), e incluso en núcleos más pequeños como Melipilla, Talagante y San Bernardo.

Para evitar que se sigan perpetuando dichos efectos -y a raíz de un paradigma que está permeando en la literatura

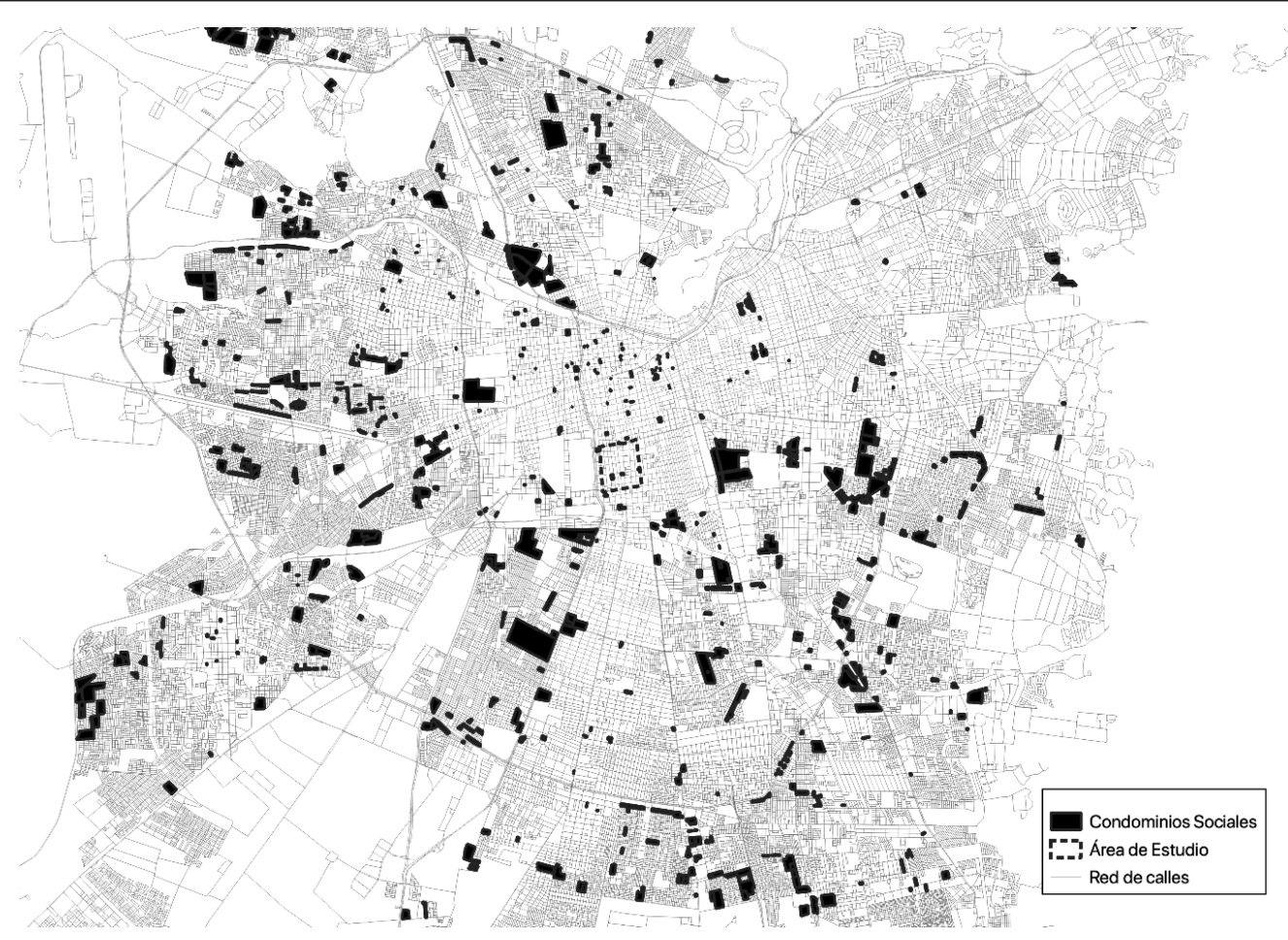

Figura 1. Catastro Nacional de condominios sociales en Santiago de Chile. Fuente: Ministerio de Vivienda y Urbanismo (2016). 
académica en Chile, tendiente a fomentar la mixtura o mezcla social (Sabatini \& Vergara, 2018)- las nuevas políticas de vivienda buscan la instalación de proyectos de integración social (PIS) en las que convivan distintos estratos en sectores consolidados dentro de la ciudad .

La mezcla social en estos nuevos proyectos del Estado ha sido sinónimo de integración, sin embargo, estudios han demostrado la poca eficiencia que han tenido los PIS en cumplir este objetivo (Ruiz-Tagle \& Romano, 2019), ya que se requieren de otros factores, políticas e incentivos en diversos ámbitos para favorecer dicha convergencia. A pesar de lo anterior, este concepto ha tomado un papel fundamental en las políticas de vivienda, tanto a nivel ministerial como local, y la concepción e implementación errada de la integración podría ser uno de los factores que explican el rechazo y resistencia por parte de los vecinos históricos a la inserción de vivienda social.

En el presente artículo se evalúan los efectos económicos y urbanos de la localización de un condominio social en un barrio consolidado de la comuna de Santiago, donde se entiende que gran parte del rechazo a la incorporación de estos proyectos se sustenta bajo argumentos económicos, referente a la devaluación del barrio y por consecuencia la desvalorización de las propiedades, así como también a la imposibilidad de encontrar compradores.

La investigación se presenta de la siguiente forma, en primer lugar, se problematiza con relación a las políticas de vivienda de interés social y cómo estas han sido influenciadas desde la perspectiva académica de la integración social y la dispersión de la pobreza. Además, se presenta el barrio de análisis y se justifica el motivo de su elección. El marco teórico de la investigación corresponde a un análisis referente a estudios sobre iniciativas de instalación de viviendas de interés social y sus efectos económicos, inmobiliarios y sociales. Los resultados se dividen principalmente en tres secciones; la primera hace referencia al análisis de la demanda basada en zonas de búsqueda; y análisis de precios de búsqueda a través de series de tiempo. El segundo apartado refiere a la oferta. Se analiza precios, stock y uf $/ \mathrm{m}^{2}$ (Unidad de Fomento, la cual posee un valor que varía según el índice de precios al consumidor en Chile, y que actualmente se aproxima a unos 35 dólares americanos). El tercer apartado muestra un análisis que evidencia el interés actual del barrio. Finalmente, se exponen las conclusiones y discusiones emergidas de la investigación.

\section{La integración social en Chile}

Según el Ministerio de Vivienda y Urbanismo (MINVU), la mezcla social en programas habitacionales se desarrolló inicialmente en 2015, a través de pilotos extraordinarios entregados mediante subsidio para sectores medios. No obstante, es posible encontrar evidencia de programas de mezcla social desde el año 2006 vinculada con la Política Urbano-Habitacional de Mejoramiento de la Calidad e Integración Social, originada en el primer gobierno de Michelle Bachelet (Ruiz-Tagle \& Romano, 2019). El año en que se consolidó como política pública fue el 2015 al establecerse el Programa de Integración Social y Territorial (Decreto Supremo, DS N¹9), que busca desarrollar conjuntos habitacionales ubicados en zonas consolidadas que tengan viviendas de sectores medios y al menos un $20 \%$ de propiedades destinadas a familias vulnerables (MINVU, 2019).

Esta medida aún no se ha concretado de forma sistemática en las políticas de vivienda en Chile, debido a las dificultades de: 1) conseguir terrenos bien localizados, 2) atraer desarrolladores inmobiliarios, 3) escasez de suficientes subsidios. Por lo tanto, las posibilidades de las familias de bajos ingresos de elegir dónde vivir continúan siendo restringidas.

Las iniciativas de integración social propuestas han generado rechazo por parte de los residentes históricos de los barrios a intervenir, tales son el caso de la comunidad ecológica en Peñalolén (Comandari, 2020), Flor del Valle en Maipú (Gil, 2016) y la Rotonda Atenas en Las Condes (Cabello \& Gutiérrez). El rechazo esgrime argumentos referentes a la posible baja del valor de las propiedades o pérdida de plusvalías futuras, que enmascara un arraigado clasismo de la sociedad chilena (Sabatini, Rasse, Mora \& Brain, 2012). A través de esta investigación se evalúan los impactos económicos e inmobiliarios tras la localización de un condominio social en Santiago.

Previo a una búsqueda de condominios sociales en Chile, se opta por investigar el condominio social localizado en la calle San Francisco $\mathrm{N}^{\circ} 1666$, reconocido como el "Neo-Cité". La elección del caso de estudio se fundamenta en que no se ha construido recientemente en Santiago otro condominio social en algún barrio acomodado o consolidado. Existen casos previos en Las Condes que datan de los años 90, específicamente en la Avenida Colón Oriente, y en Peñalolén, pero la disponibilidad y actualización de datos no hace posible considerarlos como casos de estudio. 
¿Existe un efecto asociado a la instalación de condominios sociales en barrios consolidados?

La discusión en Chile ha tenido dos aristas; una que aboga por la mixtura social de los barrios para favorecer la integración social (Arriagada, 2006; Dureau \& Bonvalet, 2002; Kaztman, 2001; Rasse, 2015; Sabatini et al., 2001; Sabatini \& Sierralta, 2006), y otra, que apela por repartir los beneficios de la ciudad de forma homogénea en el territorio sin necesidad de "mover a los pobres a la ciudad" (Ruiz-Tagle \& López, 2014). El paradigma aquí analizado corresponde al primero, es decir, se examinan los efectos devenidos de la instalación de un condominio social en un barrio consolidado.

Según estudios como los de Villamizar (2015) referidos a la segregación residencial en Colombia, el autor muestra que los efectos que se generan de la localización de condominios sociales en barrios consolidados de altos ingresos son principalmente simbólicos.

Pesquizas que analizaron los submercados de propiedades para clases altas, esperaban que la calidad de la vivienda subsidiada tuviese un impacto perjudicial en el valor de la propiedad, debido a que la vivienda subsidiada sería de menor calidad que la vivienda circundante y los inquilinos serán de menor estatus social y probablemente de una raza diferente. Sin embargo, los resultados muestran que la inclusión de viviendas sociales no afecta en términos económicos el barrio (Freeman \& Botein, 2016).

Inclusive, investigadores han llegado a resultados que contradicen los supuestos sobre la vivienda subsidiada "se podría interpretar que los resultados en esta revisión argumentan que las viviendas subsidiadas deben ubicarse en comunidades en dificultades, debido a los impactos positivos que puede traer a los vecindarios con recursos limitados" (Freeman \& Botein, 2016, p. 375).

No obstante, en Chile existe poca evidencia científica referida a los efectos que genera la instalación de un condominio de interés social en un barrio de altos ingresos, principalmente porque no suelen instalarse en estos sectores, sino más bien, se han localizado en áreas que tienen un precio de suelo inferior, lo que generalmente coincide con la periferia, patrón que se repite en gran parte de las ciudades latinoamericanas (Abramo, 2012).

Algunas investigaciones previas hacen referencia a que el discurso es integrador, "es llamativo que la mayor parte de nuestros entrevistados, independientemente de su edad, estrato socioeconómico o sexo, piense que es bueno que la gente más acomodada viva cerca de gente más pobre" (Sabatini et al., 2012, p. 172) pero la conducta es segregadora:

dos tercios de los encuestados, es decir un $65 \%$ preferirían vivir en un barrio con familias de su misma clase social y solo $17 \%$ declara que le gustaría que su barrio incorporara también familias de otras clases sociales. La actitud frente a la elección de la propia vivienda parece, al menos a primera vista, incoherente con el valor asignado a la integración residencial. (Sabatini et al., 2012, p. 177)

Con respecto al análisis de las viviendas, un estudio reciente (Orrego \& Razmilic, 2018) examinó el efecto de los condominios sociales en barrios consolidados; "los resultados muestran, de manera transversal, que no existe un cambio de precios. Por otro lado, hay una disminución leve y apenas significativa en la cantidad de transacciones mensuales tras la emisión del permiso de edificación" (Orrego \& Razmilic, 2018, p. 12).

Según Orrego \& Razmilic (2018), la investigación empírica de condominios sociales se ha basado en el análisis de precios, así también, la incidencia de estos conjuntos en tasas de criminalidad y/o el aumento de la diversidad socioeconómica de los barrios. No obstante, el análisis realizado por estos autores no considera los efectos en la oferta, demanda, en el entorno ni tampoco se toma como caso de investigación un condominio social insertado en un barrio de altos ingresos (por la falta de casos), sino más bien los casos de estudio corresponden a sectores medios.

Por tanto, la presente pesquisa busca conocer si la instalación de un condominio social particular, en una de las comunas con mayor ingreso de la Región Metropolitana genera efectos en los precios, oferta colindante y en el interés por vivir en dicho barrio. Es importante señalar que, si bien el barrio está inserto en una comuna con una alta recaudación fiscal, el barrio es diverso socioeconómicamente, lo cual explica la penetración de dicho conjunto, el cual sería imposible de localizar en un barrio homogéneo de altos ingresos.

Para el analizar los efectos que generó la instalación de un condominio de interés social, se optó por una metodología de estudio de caso, donde después de catastrar todas las iniciativas de construcción de vivienda de interés social al interior del Área Metropolitana de Santiago, se optó por analizar el condominio social San Francisco N ${ }^{\circ} 1666$ en la comuna de Santiago, barrio Matta Sur, debido a la considerable información disponible del sector en las fuentes secundarias consultadas (figura 1). 
El condominio social San Francisco $N^{\circ} 1666$ fue anunciado en 2014, construido y entregado en 2015, por lo tanto, se cuentan con información proveniente del Conservador de Bienes Raíces (CBR), Servicio de Impuestos Internos (SII) e información de los principales portales inmobiliarios del país, con lo que se analiza los efectos generados en términos inmobiliarios como también socioeconómicos.

La hipótesis del presente estudio dice relación con que las viviendas del barrio Matta Sur no fueron afectadas en términos de precios ni de demanda residencial luego de la localización del condominio social San Francisco $\mathrm{N}^{\circ}$ 1666. Así, los argumentos económicos sostenidos en contra de la instalación de condominios sociales en barrios acomodados y consolidados carecen de fundamentación.

El objetivo de esta investigación es identificar los efectos económicos e inmobiliarios que genera la localización de un condominio social en un barrio consolidado, para así refutar o aceptar la hipótesis mencionada.

Los objetivos específicos, en tanto, corresponden a:

- Conocer el comportamiento de la demanda en el barrio Matta Sur durante el período 2015-2019

- Identificar variaciones en precios y oferta inmobiliaria desencadenados por la localización de un edificio de condominio social destinado a hogares de bajos ingresos.

\section{Planteamiento del problema}

La discusión respecto a la localización de viviendas sociales en los sectores consolidados de la ciudad tiene una larga historia, principalmente el debate se ha centrado en dos paradigmas: la mixtura social y la geografía de oportunidades. Respecto a la primera, Dureau, Barbary \& Thierry (2007), Sabatini et al. (2001) y Tironi (2004) argumentan que son los barrios más desfavorecidos en la ciudad los que se deben movilizar hacia los sectores que tienen las mejores oportunidades. La crítica corresponde a que se han localizado viviendas de sectores vulnerables en barrios consolidados, en vez de llevar la "ciudad" hacia las periferias más desfavorecidas. Desde la economía política urbana (Slater, 2013; Wacquant, 2000), en tanto, se plantea que el llamado "efecto barrio" desencadenado por la concentración de población económicamente pobre y la emergencia de problemas sociales no sería tal sí en ese barrio existiera un Estado y un entramado institucional presente.

Particularmente, en Chile la discusión resurgió hace algunos años atrás, con la localización de viviendas sociales en la comuna de Peñalolén (sector oriente y acomodado de
Santiago) y en Maipú (sur-poniente), en este segundo caso, no corresponde a un barrio de altos ingresos, sino que a uno de sectores donde reside principalmente la clase media (figura 2).

El debate llegó a su punto más álgido con la oposición de los vecinos, lo que atrajo la atención de la prensa y la opinión pública, e incluso desencadenó posteriormente la promulgación de una Ley de Integración Social durante el año 2019, cuyo objetivo es contribuir a disminuir la segregación socioespacial de las grandes urbes chilenas, aunque aún hoy en día sus resultados no son visibles.

Es importante señalar, que, al contrario del caso anterior, también existen hechos donde la integración ha sido exitosa y no ha conllevado un conflicto. Este es el caso de las viviendas sociales en Colón Oriente que se han estado construyendo desde los años 90 sin que los vecinos de altos ingresos de ese sector manifiesten opiniones tan radicales como los de Rotonda Atenas y esto, quizás, porque ya han tenido la experiencia de vivir cerca de estratos de menores ingresos.

La discusión tomó una nueva directriz cuando en uno de los municipios más conservadores, históricamente gobernado por partidos políticos de derecha (Las Condes), planteó la posibilidad de construir un condominio social en el corazón de la comuna, luego de muchos años de ofertas desarrolladas exclusivamente por el mercado subsidiados por el Ministerio de Vivienda y Urbanismo.

\section{Vivienda donde no hay ciudad}

La tendencia de las políticas de vivienda promovidas desde el gobierno ha sido la localización de hogares vulnerables en la periferia de la ciudad. En los años 80 la postura fue entregar soluciones habitacionales de emergencia (por ejemplo: las llamadas casetas sanitarias, donde se entregaba un baño y cocina), hasta hoy, que a través de lógicas subsidiarias se busca la integración social. Este estudio, cabe hacer la salvedad, no profundizará sobre la historia de la vivienda social, ya que ha sido estudiada por autores como Hidalgo (2002) y Rodríguez \& Sugranyes (2006).

En un esfuerzo por hacer frente a los problemas que generó la política de vivienda social expuesta, el MINVU propuso en 2006 incluir como objetivo central de su política habitacional la búsqueda de la integración social mediante el diseño de múltiples programas y decretos. Las medidas más emblemáticas son los Proyectos de Vivienda Integración Social (PIS), que inspirados en ejemplos de mixtura social europea y australiana (Fincher, Iveson, 


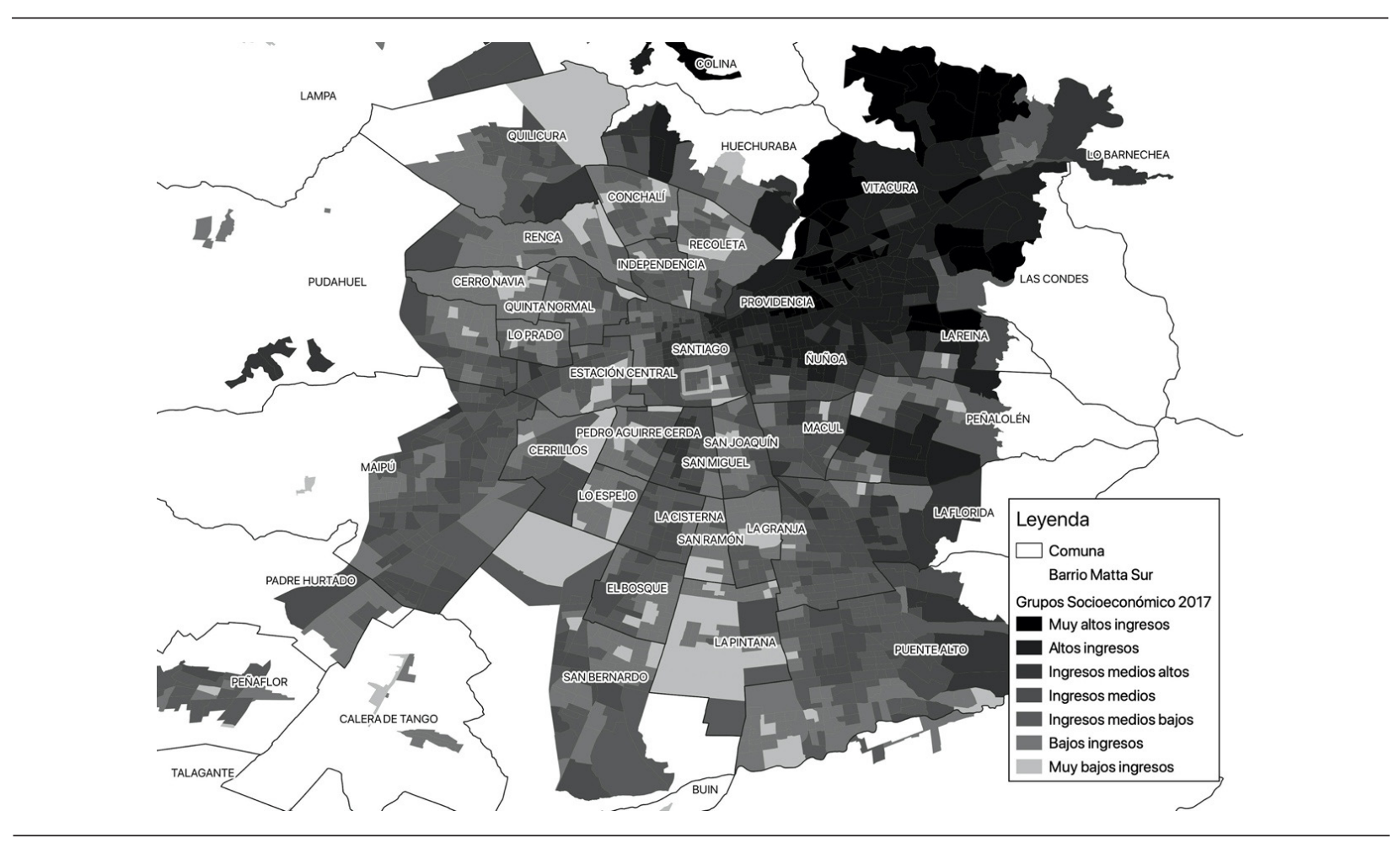

Figura 1. Grupos socioeconómicos 2017. Fuente: Observatorio de Ciudades UC (2017).

Leitner \& Preston, 2014), promueven la convivencia de grupos socioeconómicos disimiles, específicamente medios y bajos, en un mismo conjunto habitacional.

Entre los años 2006 y 2014 los PIS proponen barrios de ingresos mixtos donde convivan entre un $20 \%$ a $30 \%$ de familias pertenecientes a sectores vulnerables y entre un $20 \%$ a $80 \%$ de familias de sectores medios-bajos. Este tipo de proyecto fue considerado un 'hito político', ya que por primera vez en Chile se plantea una política urbana que promueve explícitamente la mixtura social al interior del barrio. (Maturana, Vergara \& Romano, 2016, p. 3).

Sin embargo, a pesar del interés en la mixtura social, los proyectos de vivienda de interés social se siguen desarrollando en la periferia urbana, donde existe poca diversidad social. La tabla 1 evidencia los proyectos de integración social en construcción durante el período 20192020. Solamente existen dos proyectos, en la comuna de Independencia que se encuentran próximos al área central de Santiago, en una comuna que percibe altos ingresos, todos los demás se encuentran en la periferia expandida de la ciudad, es decir, más allá de su frontera metropolitana, integrando áreas rurales adyacentes, lo que corresponde a comunas con altos déficits urbanos.
Adicionalmente, un aspecto no abordado en esta investigación, pero que podría ser una alternativa para mejorar la localización de los hogares de bajos ingresos es la recuperación de plusvalías para el financiamiento de vivienda sociales: "la recuperación de plusvalías es un tipo de financiamiento, usado por entidades del Estado, que extrae recursos desde las alzas en los valores de suelo urbano provocadas por intervenciones públicas" (RuizTagle, Labbé, Rocco, Schuster \& Muñoz, 2018, p. 115). Sin embargo, en Chile no existen mecanismos que permitan hacer dicha captura "la plusvalía producida por inversión en obras públicas, que es principalmente aprovechada por los agentes inmobiliarios privados, no es objeto de recuperación" (Páramo Lopera \& López-Morales, 2020).

\section{El proyecto Neo-Cité en San Francisco Nº 1666}

A través de un proyecto puntual en uno de los municipios con mayores ingresos de Chile, que contó con el respaldo del gobierno local y un estudio de arquitectura de renombre, además del apoyo del Ministerio de Vivienda y Urbanismo, se concretó en el año 2015 la construcción de un conjunto habitacional modelo.

El proyecto fue denominado "Neo-Cité San Francisco"y fue construido en un terreno municipal con un presupuesto 
Tabla 1

Programas de Integración Social en Chile 2019-2020.

\begin{tabular}{llll}
\hline Comuna & No de proyectos & Nombre & Tipo de proyecto \\
\hline San Bernardo & 1 & Vista Parque V & Casas \\
\hline Puente Alto & 1 & Condominio Domingo Eyzaguirre & Departamentos \\
\hline Pudahuel & 1 & Condominio Rio Viejo de Pudahuel & Departamentos \\
\hline Colina & 3 & $\begin{array}{l}\text { Condominio Escultora Lily Garafulic, } \\
\text { Condominio Escultor Nicanor Plaza, } \\
\text { Condominio Escultor Sergio Mallol }\end{array}$ & Casas \\
\hline Independencia & 2 & $\begin{array}{l}\text { Jardines de Alvarado II (Los } \\
\text { (Lamos), Jardines de Alvarado III }\end{array}$ & Departamentos \\
\hline La Pintana & 1 & Condominio Huertos de La Pintana & Departamentos \\
\hline
\end{tabular}

Fuente: MINVU (2019).

de 821 uf, lo que equivale a 30.550 dólares por vivienda ${ }^{1}$. Sus condiciones espaciales rescatan la herencia del cité, maximizando el espacio común, el enfrentamiento y la cercanía de fachadas, una accesibilidad controlada, y un sistema de circulaciones simple y volcado hacia el espacio público central (figura 3).

(...) el proyecto se construye a partir de la tipología de cité, ya que es un referente arquitectónico tradicional del barrio. Son dos brazos en paralelo que están puestos en perpendicular a la calle y se desarrollan hacia el fondo del sitio con una escala entre 3 y 4 pisos. Las viviendas de entre 55 y $70 \mathrm{~m} 2$ se ordenan en torno a un patio donde se desarrolla la vida comunitaria. (Theoduloz, 2016, p.1)

\section{Materiales y métodos}

\section{Barrio Matta Sur}

El barrio Matta Sur, un barrio histórico de la comuna de Santiago, tuvo unos orígenes humildes: "que hasta mediados del siglo XIX estaba conformado por chacras que abarcaban desde la propia Cañada hasta el Zanjón de la Aguada, y por pequeños poblados. Estos poblados se agruparon en torno a las calles Carmen, Santa Rosa y San Isidro, las cuales desde finales del siglo XVIII fueron orientando el crecimiento de la ciudad hacia el Sur" (Consejo de Monumentos Nacionales de Chile, 2019).

La difícil vida en el barrio se mantuvo en torno a chacras y pobreza entre sus habitantes hasta finales del siglo XIX. Sin embargo, con el transcurrir del tiempo se realizó un proceso de consolidación a través de la construcción de propiedades de un piso hasta mediados del siglo XX. La actual composición poblacional principal son hijos de los antiguos habitantes de estratos socioeconómicos medios, quienes han ocupado las propiedades bajo el concepto de un barrio residencial.

Hoy en día, lo atractivo de la ubicación ha captado un interés mayor de las inmobiliarias permitiendo la continua proliferación de proyectos que han modificado la estructura original. Lo anterior, provocó una reacción de los vecinos por medio de comités de defensa en contra de los desarrolladores y todo aquello que promueva la destrucción del patrimonio cultural de barrio Matta Sur. Las acciones realizadas permitieron que durante el año 2015 una parte del barrio fuese declarado como patrimonial, así dejando protegido el legado histórico del barrio Matta Sur (Colin, 2020). Estas acciones de defensa, según Colin (2020), principalmente responden a la construcción colectiva de la idea de barrio bajo el concepto de la territorialización de la nostalgia que diferencia a los habitantes presentes

${ }^{1}$ Dólar observado: $\$ 800$. 


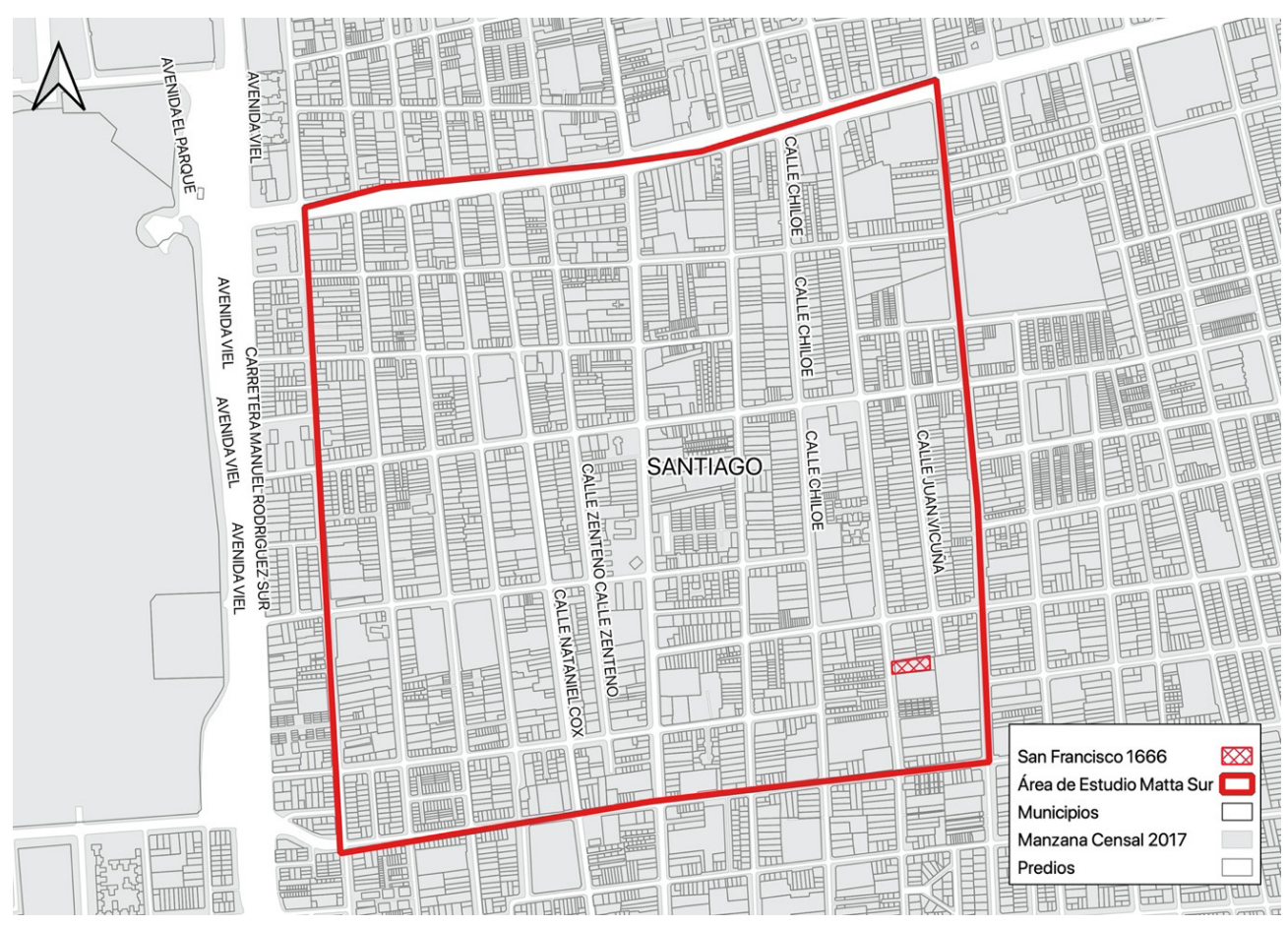

Figura 3. Área de estudio, barrio Matta Sur, comuna de Santiago. Fuente: Observatorio de Ciudades UC (2017).

desde los orígenes de los llegados a partir de los proyectos inmobiliarios, quienes no comparten la misma identidad presente en el lugar.

Es importante señalar que el instrumento de planificación territorial vigente es el Plan Regulador Comunal (PRC) de Santiago -cuya última actualización corresponde a julio del año 2019-. El barrio se encuentra en una zona definida por el PRC como Macrozona E, la que posee normas de constructibilidad bastante estrictas.

A través de un análisis de caso, tomando como área de influencia (AI) el barrio Matta Sur donde se circunscribe el condominio social San Francisco $N^{\circ} 1666$, se utilizó una metodología cuantitativa, que buscó aislar e identificar el efecto que genera la localización de un conjunto habitacional de bajos ingresos.

Para ello se utilizaron tres fuentes de información: las inscripciones del Conservador de Bienes Raíces, en las cuales se registra el dominio de un inmueble y su precio de compra para así realizar una evaluación de los precios desde los años 2014 a 2016; la base de datos del Servicio de Impuestos Internos referente a los avalúos del año 2018 que caracteriza las propiedades del barrio; y finalmente, los registros de publicaciones del período 2015-2020 facilitados por la página web Goplaceit para un análisis de las variaciones económicas de las ofertas publicadas.

\section{Resultados}

En primer lugar, se analiza la demanda con datos facilitados por el portal de publicación. La figura 4 muestra la evolución histórica de la demanda residencial en el barrio y en la comuna de Santiago (figura 5), representado por la creación de zonas (eje Y), las zonas corresponden a polígonos dibujados por los usuarios en el portal inmobiliario de dónde buscan vivir (tanto para arriendo como para venta). Se evidencia el declive desde el año 2018 para arriendo en el barrio y mucho más fluctuante en el caso de la comuna de Santiago, con repuntes durante el primer semestre del 2018 y primer semestre 2019. En cambio, para el caso de personas que buscan comprar, la curva en el barrio Matta Sur evidencia estabilidad desde el año 2018. Es decir, el sector es menos atractivo en términos de arriendo comparativamente desde 2016 a 2019, pero es igual de atractivo para quienes buscan comprar.

Por tanto, de las figuras anteriores es factible concluir que, si bien el interés en el barrio disminuyó para el caso de las personas que buscaban arriendos, esto no solo sucedió 


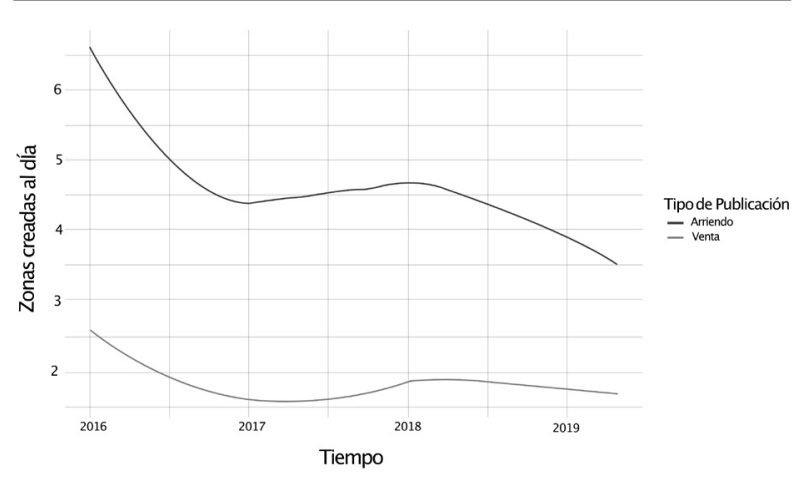

Figura 4. Creación de zonas en barrio Matta Sur 2016-2020 Fuente: elaboración propia con base en página web Goplaceit (2020).

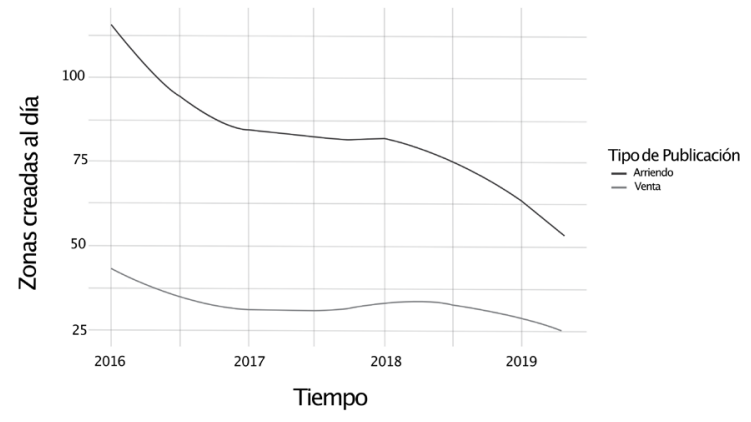

Figura 5. Creación de zonas en el área de influencia y en la comuna de Santiago 2016-2020. Fuente: elaboración propia con base en página web Goplaceit (2020).

en el barrio, sino que también ocurrió para la totalidad de la comuna de Santiago.

En términos generales, en la comuna de Santiago los usuarios crearon 126.356 zonas de búsqueda ${ }^{2}$ durante el período analizado, y en el barrio se crearon un total de 6.426 , lo que equivale a un $5 \%$ de las zonas de búsqueda en la comuna. Con esto, se establece que el sector es de mediano interés en comparación con otros barrios de la comuna $^{3}$ que acaparan una mayor cantidad de zonas.

Con respecto a las características de la búsqueda, es factible conocer y analizar la evolución de los precios de búsqueda en el tiempo para arriendos y ventas. Con respecto a los primeros, estos han ido al alza sustancialmente, tanto para la comuna como para el barrio, esto significa que no ha habido cambios significativos que hagan disminuir la valorización que hacen los usuarios del barrio como tampoco de la comuna.

Es importante recalcar que si bien, el análisis anterior mostraba una disminución en el interés de vivir en el barrio (por la cantidad de zonas creadas), esto no puede ser atribuido a cambios en el mismo, ya que como se constata con los precios, la valorización que hacen los usuarios respecto a este ha ido en alza. Incluso la disminución de búsquedas en el barrio puede ser consecuencia de cambios demográficos o incluso de estilos de vida, como también contexto social y de crisis, que ha generado que la gente esté menos interesada en vivir en el centro (Labbé, 2020).

Los precios de arriendo que se evidencian en la figura 6 están detallados por número de habitaciones. Para el caso de la comuna de Santiago en promedio el valor es de $\$ 325.000$ pesos chilenos (USD \$419) para un departamento en arriendo de un dormitorio, en barrio Matta Sur el precio en promedio es levemente sobre los \$300.000 (USD \$387), es decir, las personas valorizan en promedio un $8,3 \%$ más los departamentos en la comuna de Santiago por sobre el barrio Matta.

Las valorizaciones que fueron evidenciadas para el barrio Matta Sur son comparables con comunas como San Miguel (USD \$438) y La Florida (USD \$483). En el caso de San Miguel, la contigüidad con esta podría explicar la similitud en la valorización que hacen los usuarios, en el caso de La Florida, si bien los precios son levemente más elevados, entre los atributos urbanos que destacan, al igual que barrio Matta Sur, son el acceso a servicios y equipamientos debido a su condición de buena accesibilidad para servicios y equipamientos.

Los precios de búsqueda de arriendo han variado de manera significativa en el transcurso del período analizado, para departamentos de un dormitorio, ha aumentado en un $24 \%$, departamentos de dos dormitorios han aumentado un $30 \%$ y para tres dormitorios han aumentado un $29,73 \%$ (figura 7).

Con respecto a la misma información, pero para el caso de personas que buscan comprar, y que al igual que quienes buscan arriendo valorizan cada año a un precio más alto su búsqueda. Los precios dependen también del tamaño

${ }^{2}$ Hace referencia a zonas de búsquedas que corresponde a zonas dibujadas por los usuarios en el barrio de interés declarado al ingresar en el portal web donde están buscando su futura viviendas, ya sea para arrendar o comprar.

${ }^{3}$ Los otros barrios que presentaron un mayor interés por parte de los usuarios del portal están localizados principalemente en el sector norte de la comuna de Santiago. 


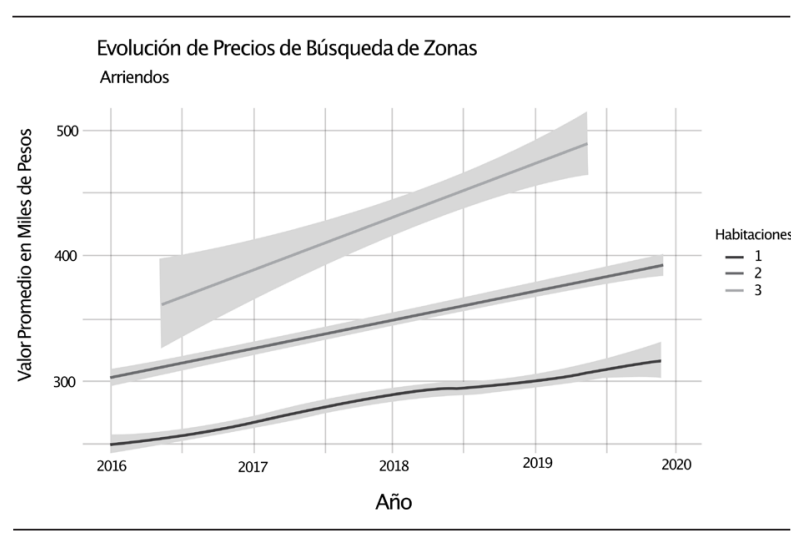

Figura 6. Precios de búsqueda en el área de influencia por modalidad 20162020. Fuente: elaboración propia con base en página web Goplaceit (2020).

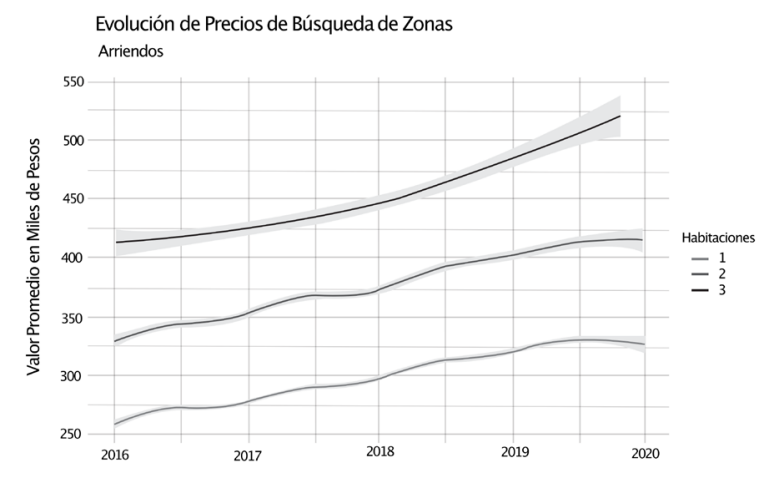

Figura 7. Precios de búsqueda en el área de influencia y en la comuna por modalidad 2016-2020. Fuente: elaboración propia con base en datos de página web Goplaceit (2020).

del inmueble. La figura 8 muestra la evolución de precios de búsqueda según número de habitaciones para el barrio Matta Sur. Para departamentos de un dormitorio, los precios hoy alcanzan casi las 2.500 UF $\left(87.500 \mathrm{USD}^{4}\right)$. Los departamentos más costosos corresponden a los de tres dormitorios con un valor de búsqueda de 3.500 UF (122.500 USD). Si se contrasta este valor con las búsquedas que había a comienzos del 2016, los valores han variado un $38,89 \%$ para un dormitorio, $7,6 \%$ para dos dormitorios y $-2,7 \%$ para el caso de tres dormitorios (en el último período) pero no ha dejado de crecer desde el 2016.

Por tanto, se concluye que la instalación del conjunto de interés social Neo-Cité no ha impactado de forma negativa la valorización que hacen los usuarios del sector, todo lo contrario, ya que estos van en alza a excepción de los precios de venta de departamentos que entre 2019-2020 fluctuó de forma negativa con $-2,7 \%$. El peak de aumento corresponde a los departamentos de un dormitorio con un $38,9 \%$.

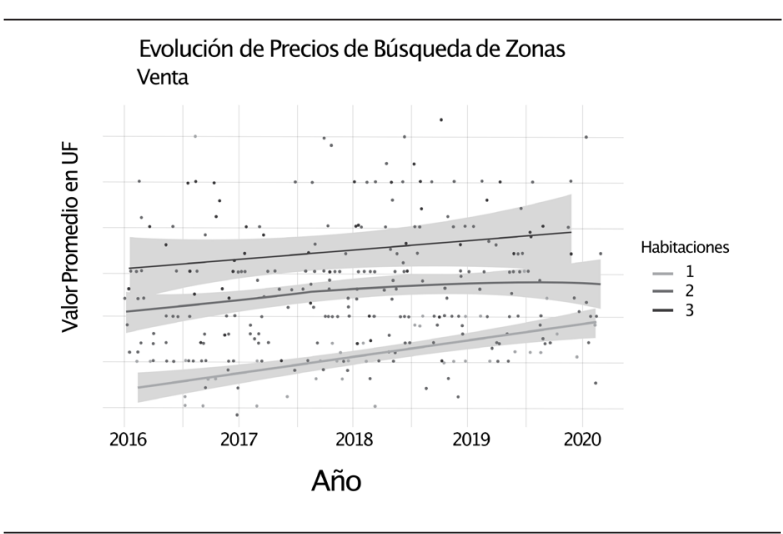

Figura 8. Precios de búsqueda en el área de influencia 2016-2020. Fuente: elaboración propia con base en datos de página web Goplaceit (2020).

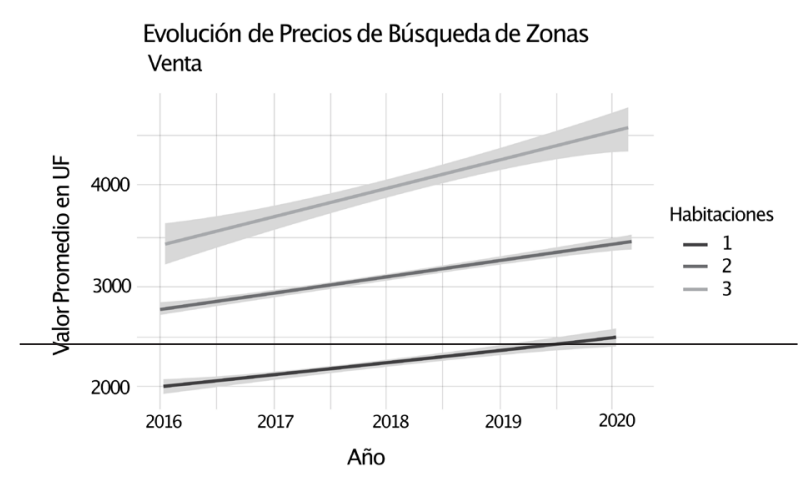

Figura 9. Precios de búsqueda en el área de influencia 2016-2020. Fuente: elaboración propia con base en datos de página web Goplaceit (2020).

Con respecto a la valorización promedio a las zonas en Santiago, la figura. 9 muestra que la tendencia es que los precios vayan al alza, por tanto, si hubiese un efecto derivado de la instalación del condominio de interés social en el barrio Matta Sur, se debería haber reflejado en las valorizaciones, cosa que no ocurrió, sino todo lo contrario, los precios van al alza y siguen la tendencia de la comuna.

\section{Oferta}

Se analizó la oferta publicada en el período de tiempo 2016-2020 y se evidencia que el mayor número de publicaciones corresponden a departamentos. La mayor cantidad de publicaciones se encuentran al centro del barrio, alejadas del proyecto Neo-Cité, ya que este está rodeado de viviendas de baja densidad. En cambio, al centro del barrio hay una mayor oferta de departamentos. Sin duda, el destino de vivienda menor en el barrio corresponde al de "oficinas", por lo tanto, se deduce que es un barrio principalmente destinado a la residencia (figura 10).

${ }^{4}$ Dólar observado: \$800; UF observada: \$28.700 


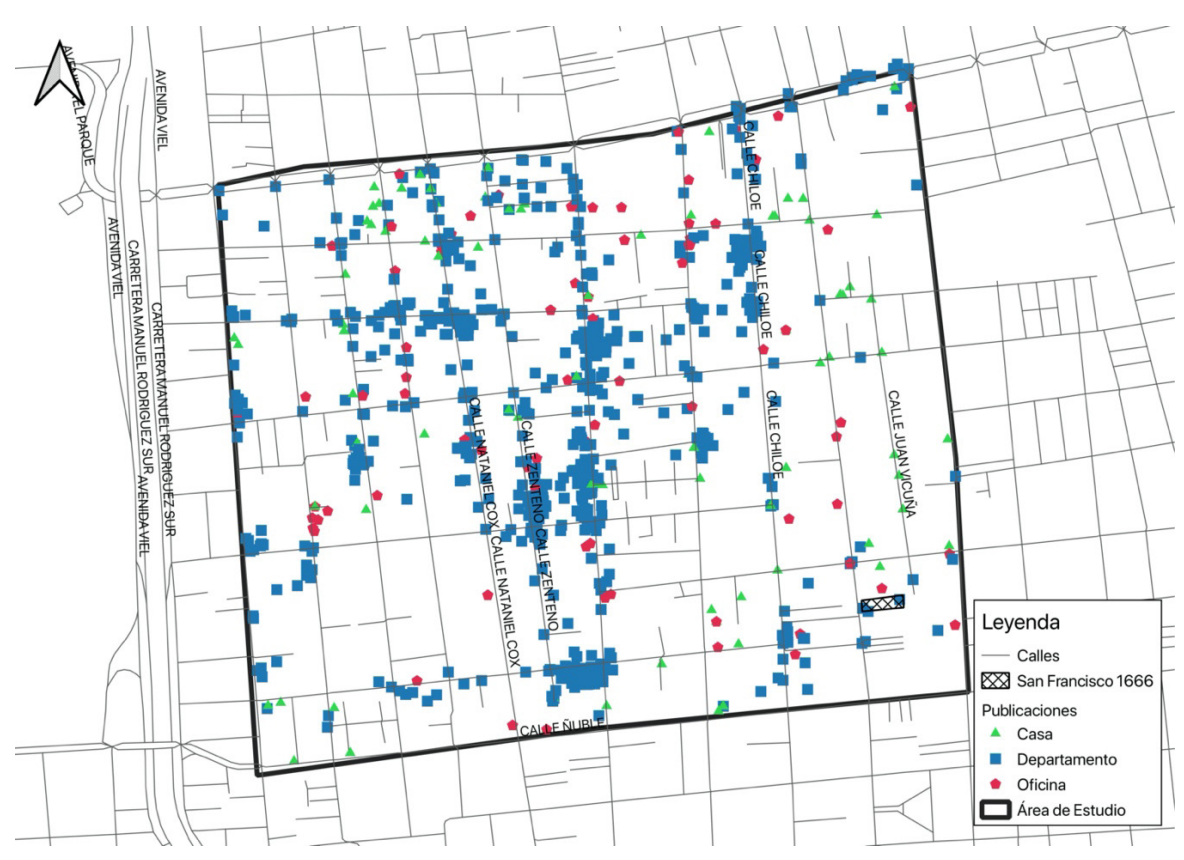

Figura 10. Publicaciones en el área de estudio 2016-2020. Fuente: elaboración propia con base en publicaciones de página web Goplaceit (2020).

Con respecto al total de oferta, la figura 11 muestra la evolución histórica de las publicaciones, se evidencia que el número ha crecido, teniendo su mayor peak en el primer cuatrimestre 2019 para arriendo, y el primero y último cuatrimestre para venta.

Si bien, las publicaciones han aumentado, esto tiene que ver con la construcción y habilitación de edificios cercanos en el sector durante el período estudiado, además se constata que la crisis social vivida en Chile durante el 18 de octubre de 2019 no repercutió en un mayor stock de viviendas disponibles para venta o arriendo, esto debido a que los mayores stocks ocurrieron el primer semestre de 2019, antes de la crisis social.

Esto quiere decir que no ha habido una fuga de arrendatarios como sucedió en otros barrios (como es el caso de Baquedano, centro neurálgico de la comuna de Santiago, expuesto a las manifestaciones públicas). En términos de la venta, puede significar que los propietarios no están liberando propiedades para venta, frente a la expectativa que los precios pueden bajar ${ }^{5}$ (figura 11).

Finalmente, se muestra la evolución $\mathrm{uf} / \mathrm{m}^{2}$ del sector. Si bien la construcción del condominio de interés social se

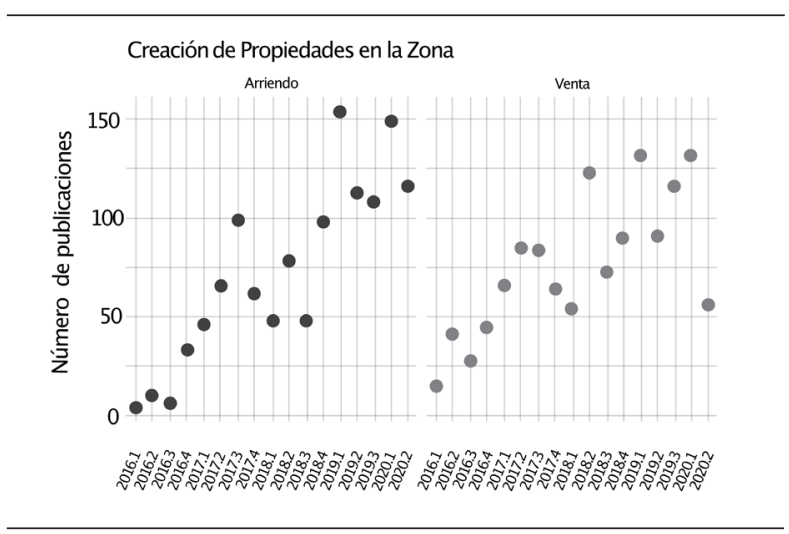

Figura 11. Publicaciones en el área de estudio 2016-2020. Fuente: elaboración propia con base en publicaciones de página web Goplaceit (2020).

concretó durante el 2015, los precios publicados no han sufrido fluctuaciones a la baja (a excepción de una caída durante el segundo semestre de 2019 para departamentos de tres habitaciones), todas las modalidades han ido en alza. Por tanto, se descarta que la instalación de un condominio de interés social haya desencadenado una desescalada en los precios de oferta, así como en la demanda (figura 12).

Adicionalmente, se analizan los datos del Conservador de Bienes Raíces relativos a las compras de propiedades,

${ }^{5}$ Ver https://map.conectamedia.cl/index.php/clippingNews/view?id=13289903\&email=153100\&fromemail=1 


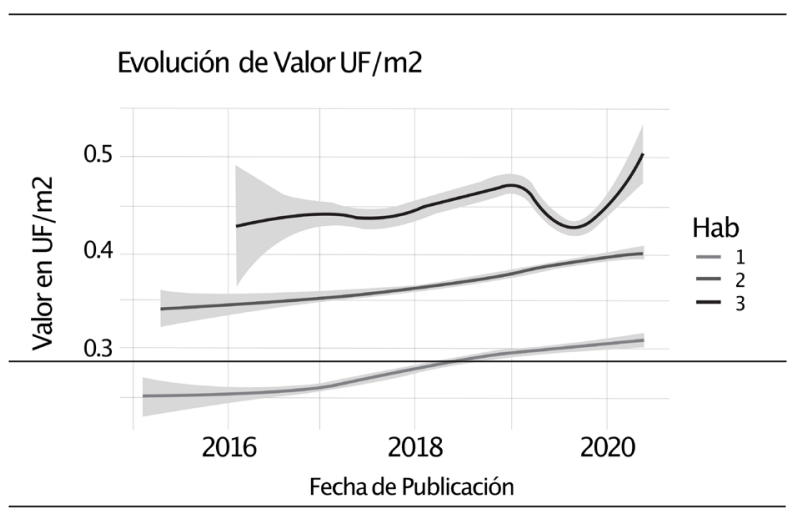

Figura 12. Evolución UF/m2 en el área de estudio 2016-2020. Fuente: elaboración propia con base en página web Goplaceit (2020).

lo cuales permiten comprender la dinámica inmobiliaria que ocurre en el sector. El Conservador de Bienes Raíces registra de manera oficial las transacciones de bienes raíces en el país.

El análisis de los datos de transacciones obtenidos desde el Conservador de Bienes Raíces permite conocer que tan atractiva y dinámica es el área en comparación con otros sectores de la Región Metropolitana. La metodología utilizada buscó identificar dónde compran los inversionistas, para ello se agruparon los RUT que han comprado entre 5-50 propiedades en un período de tiempo que va desde 2012-2016.
La figura 13 evidencia el panorama general de inversionistas en la Región Metropolitana, pero también se visualiza el polígono que corresponde al barrio Matta Sur. El área de estudio se ubica en una zona de interés mayor para inversionistas, como lo es la comuna de Santiago donde se han tranzado entre 7.000 a 21.000 roles a inversionistas.

\section{Discusión}

Particularmente en la última década, los formuladores de políticas de vivienda han fomentado la dispersión de viviendas subsidiadas (Hidalgo, 2002; Sabatini et al., 2001). Las políticas de vivienda en Chile, bajo la justificación de la necesidad de disminuir el déficit habitacional, consolidaron un sistema subsidiario y tercerizado al mundo privado (Fuster-Farfán, 2019). Este sistema permitió a la dupla Estado-Desarrolladores privados-Dueños del suelo la consolidación de una periferia cimentada en viviendas de interés social, completamente alejadas de los centros, colegios y oportunidades en general.

Posterior a la construcción y consolidación de las periferias santiaguinas, vino la retracción institucional generalizada, tanto público como privado (Ruiz-Tagle \& López, 2014), desencadenando múltiples problemas sociales que se perpetúan hoy en las principales poblaciones chilenas (Labbé, 2018), como son las altas tasas delictuales, los problemas y la estigmatización territorial (Álvarez, 2017).

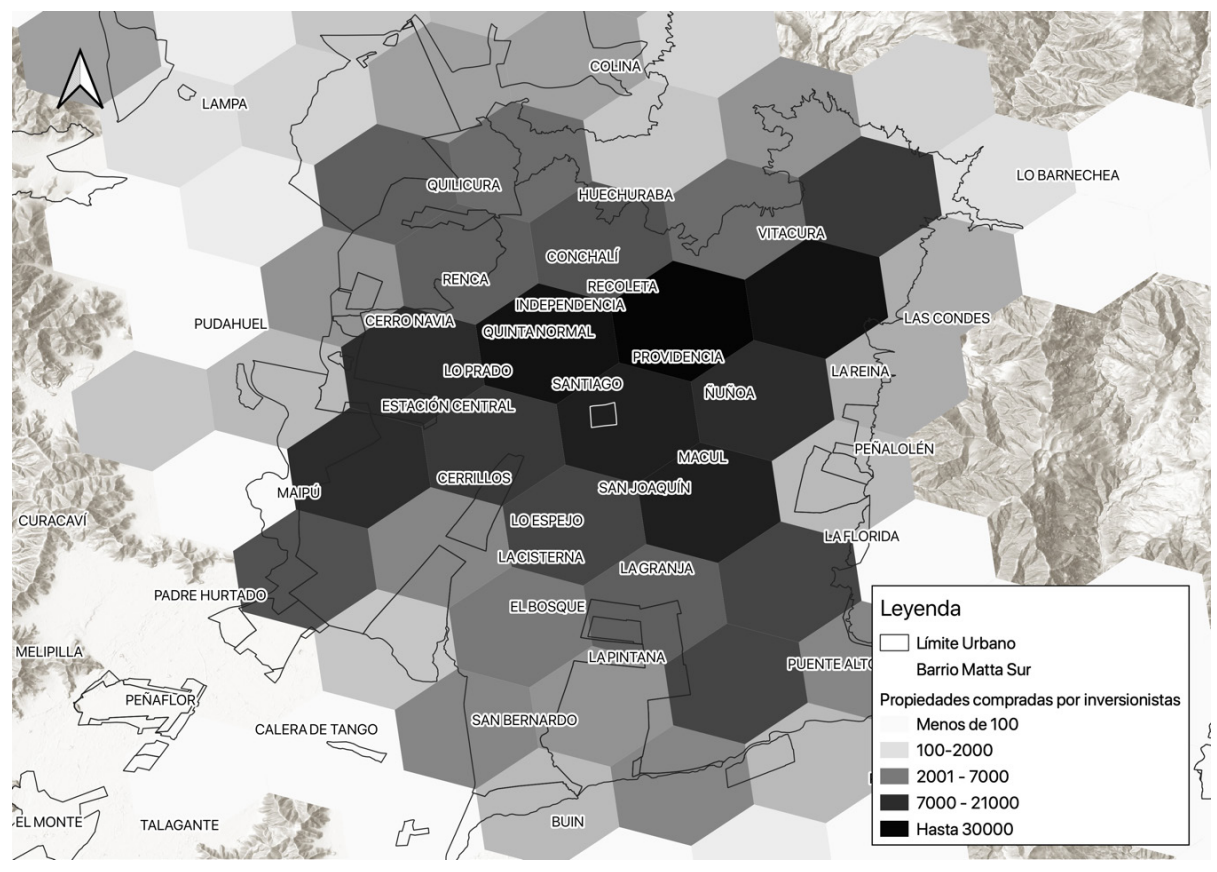

Figura 13. Propiedades compradas por inversionistas 2012-2016. Fuente: Conservador de Bienes Raíces (2020). 
Es por este motivo que la instalación de proyectos de interés social en cualquier barrio genera tantos resquemores, puesto que se le asociaría directamente con el surgimiento de problemas sociales.

Sin embargo, los problemas sociales y las patologías urbanas no están en los barrios, sino más bien aparecen cuando instituciones que operan sobre ellas lo hacen de forma intermitente, descoordinada, corrupta y poco eficiente (Labbé, 2018; Ruiz-Tagle \& López, 2014), por lo tanto, la instalación de un condominio de interés social en un barrio con presencia institucional eficaz no debería desencadenar dichos problemas, sino todo lo contrario, puede ser una oportunidad para que los residentes accedan a servicios y equipamientos de mejor calidad en comunas que pueden invertir más en ello.

En el caso del proyecto Neo-Cité existe un interés institucional (municipio) por generar viviendas de mejor calidad y dejar de expulsar a los residentes históricos, que están en condición de allegamiento, hacia barrios periféricos. Pero también se debe poner en tela de juicio que no es factible "mover a los pobres a la ciudad", sino más bien se debe apuntar por repartir los beneficios de la ciudad de forma homogénea en el territorio (Ruiz-Tagle \& López, 2014).

Por lo tanto, la importancia del proyecto Neo-Cité radica en que se constituye como una iniciativa que se encuentra ubicada en una zona de alta plusvalía en el centro de la ciudad:

una funcionaria de la gerencia técnica de Vivienda del Municipio de Santiago señaló que, hasta la fecha, estábamos erradicando a las familias pobres de la comuna a la periferia de Santiago, aspecto que motivó aún más al Municipio a invertir en este proyecto (Fuster-Farfán, 2019, p. 16).

Además, este proyecto no genera efectos significativos en la demanda residencial en el barrio, ni tampoco en la oferta.

(...) Marta (45) y Carmen (74) coinciden en que la posibilidad de quedarse en la comuna y contar con departamentos de gran tamaño en comparación con sus anteriores viviendas las posiciona en una condición de "privilegio". De hecho, según el representante de la Entidad Patrocinante, "la gente iba a preguntar dónde estaba la sala de ventas", confundiendo este proyecto con uno dispuesto en el mercado inmobiliario. (Fuster-Farfán, 2019, p. 17)
Este estudio podría ser un precedente para sopesar los efectos devenidos de la instalación de vivienda subsidiada en barrios consolidados. Incluso, es relevante al considerar que son varios los municipios de sectores acomodados de la ciudad que están planteando la posibilidad de construir viviendas de interés social en sus territorios, pero que han tenido que congelar sus proyectos, debido a la negativa los residentes. La investigación coincide plenamente con lo evidenciado por Orrego \& Razmilic (2018), cuyos resultados muestran que no existe un cambio de precios.

Así esta pesquisa demuestra que no existen efectos significativos en los precios y en la demanda al localizar un condominio de interés social. Si bien, se ve una baja en la demanda del sector, esto no pudo ser atribuida a la localización de un conjunto social, sino más bien respondió a una tendencia comunal de pérdida de interés.

\section{Limitantes}

Se declaran tres principales limitantes en este estudio: 1 ) no existen condominios sociales construidos desde 2015 en áreas acomodadas en Chile, por lo tanto, la disponibilidad de casos de estudio para el análisis es nula; 2) a través de los datos analizados, no es posible saber si quienes hicieron búsquedas en el portal inmobiliario en el área de estudio sabían de la existencia de un condominio social y 3 ) no existen datos de transacciones, debido a que esta información si bien es pública, no está sistematizada en una base de datos, por tanto solo podemos conocer la magnitud del fenómeno (que fue expresado en compras de inversionistas, pero no los valores).

\section{Conclusiones}

En términos de demandas anteriores, es factible concluir que si bien el interés en el barrio disminuyó para el caso de las personas que buscaban arriendos (traducido en la creación de menos zonas), no sucedió solo en el barrio, sino que también ocurrió para la totalidad de la comuna de Santiago.

La disminución en el interés en el barrio no puede ser atribuido a cambios en el mismo, ya que como se constata con los precios, la valorización que hacen los usuarios respecto a este ha ido en alza. Como se mencionó anteriormente, la disminución de búsquedas en el barrio puede ser consecuencia de cambios demográficos o incluso de estilos de vida, como también contexto social y de crisis, que ha generado que la gente esté menos interesada en vivir en el centro. 
Los precios de búsqueda de arriendo han variado de manera significativa en el transcurso del período analizado, para departamentos de un dormitorio, ha aumentado en un $24 \%$, departamentos de dos dormitorios han aumentado un $30 \%$ y para tres dormitorios han aumentado un $29,73 \%$. Esto va más allá del alza normal que tienen los precios de forma anual, sino que incluso puede ser interpretado como una mayor demanda.

Con respecto a la oferta, se evidencia que el número de publicaciones ha ido en aumento, es decir, se han publicado una mayor cantidad de propiedades. La oferta en el barrio tuvo su mayor peak en el primer cuatrimestre 2019 para arriendo, y el primero y último cuatrimestre para venta. Si bien, las publicaciones han aumentado, esto tiene que ver con la construcción y habilitación de edificios cercanos en el sector durante el período estudiado.

Además, se constata que la crisis social vivida en Chile durante el 18 de octubre de 2019 no repercutió en un mayor stock de viviendas disponibles para venta o arriendo, esto debido a que los mayores stocks ocurrieron el primer semestre de 2019, antes de la crisis social. Por tanto, se deduce que este sector no ha sido tan impactado por la crisis social y/o pandemia, ya que no existió una fuga de arrendatarios como evidenciaron otros barrios de la comuna.

Como se señaló anteriormente, el IPT vigente tiene normas de edificación bastante estrictas en términos de altura y pisos, esto ha permitido que el barrio se conserve como un sector de baja altura. Esto podría abrir un flanco a futuras investigaciones sobre la renovación urbana, a través de la instalación de un condominio de interés social en un barrio que regula fuertemente el desarrollo inmobiliario y sus consecuentes efectos.

Finalmente, el análisis de la evolución uf $/ \mathrm{m}^{2}$ del sector muestra que los precios han variado hacia el alza en las modalidades, a excepción de una pequeña caída el segundo semestre 2019 -en las viviendas de tres habitaciones-, lo que rechaza la afirmación que la introducción de condominio de interés social en un barrio consolidado haya afectado los precios de oferta y la demanda.

\section{Agradecimientos}

GOPLACEIT.COM por los datos facilitados.

\section{Referencias}

Abramo, P. (2012). La ciudad com-fusa: Mercado y producción de la estructura urbana en las grandes metrópolis latinoamericanas. Revista EURE - Revista de Estudios Urbano Regionales, 38(114). Recuperado de https://www.eure.cl/index.php/eure/article/view/68

Álvarez, M. (2017). Efectos de la estigmatización territorial en los residentes de la población Santo Tomás, La Pintana (Tesis de Magíster). Pontificia Universidad Católica de Chile. Recuperado de https://estudiosurbanos.uc.cl/exalumnos/efectos-dela-estigmatizacion-territorial-en-los-residentes-de-lapoblacion-santo-tomas-la-pintana/

Arriagada, I. (2006). Cambios de las políticas sociales: Políticas de género y familia. Revista CEPAL, Repositorio digital, 119. Recuperado de https:// repositorio.cepal.org//handle/11362/6122

Cabello, N., \& Gutiérrez, P. (10 de julio de 2018). Rechazo de vecinos a viviendas sociales en Las Condes abre debate sobre integración social. Economía y negocios online. Recuperado de http://www.economiaynegocios. $\mathrm{cl} /$ noticias/noticias.asp? $\mathrm{id}=486109$

Colin, C. (2020). Del miedo al orgullo: Emociones que conducen la movilización patrimonial. El caso del barrio Matta Sur, Santiago de Chile. Revista Latinoamericana de Estudios sobre Cuerpos, Emociones y Sociedad, 22. Recuperado de http://www.relaces.com. ar/index.php/relaces/article/view/91

Comandari, P. (30 de enero de 2020). Proyecto de viviendas sociales divide a la comunidad ecológica de Peñalolén. T13 móvil. Recuperado de https:/www. 七13.cl/noticia/nacional/proyecto-viviendas-socialesdivide-comunidad-ecologica-penalolen

Consejo de Monumentos Nacionales de Chile. (2019). Barrio Matta Sur. Recuperado de https://www. monumentos.gob.cl/monumentos/zonas-tipicas/barriomatta-sur

Dureau, F., Barbary, O., \& Thierry, L. (2007). Dinámicas metropolitanas de poblamiento y segregación. En Françoise Dureau, Olivier Barbary, V. Gouëset, O. Pissoat \& T. Lulle (coords.), Ciudades y sociedades en mutación: lecturas cruzadas sobre Colombia (pp. 163-235). 
Dureau, F., \& Bonvalet, C. (2002). Los modos de habitar: Unas decisiones condicionadas. En E, Dupont, J. Levy \& T. Lulle (Eds.), Metrópolos en movimiento: Una comparación internacional (pp. 69-87).

Fincher, R., Iveson, K., Leitner, H., \& Preston, V. (2014). Planning in the multicultural city: Celebrating diversity or reinforcing difference? Progress in Planning, 92, 1-55. https://doi.org/10.1016/j. progress.2013.04.001

Freeman, L., \& Botein, H. (2016). Subsidized Housing and Neighborhood Impacts: A Theoretical Discussion and Review of the Evidence. Journal of Planning Literature,16(3). https://doi. org/10.1177/08854120222093419

Fuster-Farfán, X. (2019). Las políticas de vivienda social en Chile en un contexto de neoliberalismo híbrido. Revista EURE - Revista de Estudios Urbano Regionales, 45(135). Recuperado de https://www. eure.cl/index.php/eure/article/view/2906

Gil, D. (17 de agosto de 2016). El rechazo de Maipú a la vivienda social y la dimensión institucional de la segregación residencial. Ciper. Recuperado de https:// www.ciperchile.cl/2016/08/17/el-rechazo-de-maipu-ala-vivienda-social-y-la-dimension-institucional-de-lasegregacion-residencial/

Hidalgo, R. (2002). Vivienda social y espacio urbano en Santiago de Chile. Una mirada retrospectiva a la acción del Estado en la primeras décadas del siglo XX. Revista EURE - Revista de Estudios Urbano Regionales, 28(83). Recuperado de http://www.eure. cl/index.php/eure/article/view/1220

Kaztman, R. (2001). Seducidos y abandonados: El aislamiento social de los pobres urbanos. Revista CEPAL, Repositorio digital, 75, 171-189. Recuperado de https://repositorio.cepal.org//handle/11362/10782

Labbé, G. (2018). “Vivir en un hipergueto”. Abandono estatal, retracción institucional generalizada y problemas sociales asociados en la población Santo Tomás, La Pintana (Tesis de Magíster). Pontificia Universidad Católica de Chile. Recuperado de https:/estudiosurbanos.uc.cl/exalumnos/vivir-en-unhipergueto-abandono-estatal-retraccion-institucionalgeneralizada-y-problemas-sociales-asociados-en-lapoblacion-santo-tomas-la-pintana/
Labbé, G. (30 de abril de 2020). COVID-19 + Estallido social ¿Qué tan vulnerable es el mercado inmobiliario? Medium. Recuperado de https:// medium.com/goplaceit-datos/crisis-y-mercadoinmobiliario-en-chile-es-el-mercado-del-arriendo-elm\%C3\%A1s-vulnerable-e87759cf7ac1

López-Morales, E. (2013). Gentrificación en Chile: Aportes conceptuales y evidencias para una discusión necesaria. Revista de geografía Norte Grande, 56, 31-52. https://doi.org/10.4067/S071834022013000300003

Maturana, B., Vergara, L., \& Romano, S. (2016). Vivienda pública de mixtura social en la ciudad neoliberal: Dinámicas de integración social en Villa Las Araucarias, La Serena, Chile. Contested Cities, artículo 2-516.

Ministerio de Vivienda y Urbanismo, MINVU. (2019). Subsidio de Integración Social y Territorial, DS19. Recuperado de http://www.minvu.cl/beneficio/ vivienda/subsidio-de-integracion-social-y-territorialds19/

Mora, P., Sabatini, F., Fulgueiras, M., \& Innocenti, D. (2014). Disyuntivas en la política habitacional chilena. Notas Públicas, 3. Recuperado de https:// politicaspublicas.uc.cl/publicacion/notas-publicas/ notas-publicas-n-3-disyuntivas-en-la-politicahabitacional-chilena/

Orrego, J., \& Razmilic, S. (2018). Viviendas sociales: ¿por qué no en mi patio trasero? Puntos de Referencia, 493. Recuperado de https:/www.cepchile.cl/cep/ puntos-de-referencia/puntos-de-referencia-2010-2020/ puntos-de-referencia-2018/viviendas-sociales-por-queno-en-mi-patio-trasero

Páramo Lopera, C., \& López-Morales, E. (2020). Principios, progresividad y factibilidades de la recuperación de "plusvalías" urbanas en el Chile actual. Revista de geografia Norte Grande, 76, 121-142. https://doi.org/10.4067/S071834022020000200121

Rasse, A. (2015). Juntos, pero no revueltos. Procesos de integración social en fronteras residenciales entre hogares de distinto nivel socioeconómico. Revista EURE - Revista de Estudios Urbano Regionales, 41(122). Recuperado de https://www.eure.cl/index. php/eure/article/view/559 
Rodríguez, A., \& Sugranyes, A. (2006). Los con techo. Un desafío para la política de vivienda social. EURE (Santiago), 32(95), 124-125. https://doi.org/10.4067/ S0250-71612006000100008

Ruiz-Tagle, J., Labbé, G., Rocco, V., Schuster, J. P., \& Muñoz, J. C. (2018). Recuperación de plusvalías para financiar la inserción de viviendas sociales en barrios consolidados. En I. Irarrázabal, E. Piña, M. Letelier \& M.I Jeldes (Eds.), Propuestas para Chile: Concurso de Políticas Públicas 2018 (pp. 115-161). Pontificia Universidad Católica de Chile. Recuperado de https:// estudiosurbanos.uc.cl/en/publicacion/recuperacion-deplusvalias-para-financiar-la-insercion-de-viviendassociales-en-barrios-consolidados/

Ruiz-Tagle, J., \& López, E. (2014). El estudio de la segregación residencial en Santiago de Chile: Revisión crítica de algunos problemas metodológicos y conceptuales. Revista EURE - Revista de Estudios Urbano Regionales, 40(119). Recuperado de https:// eure.cl/index.php/eure/article/view/393

Ruiz-Tagle, J., \& Romano, S. (2019). Mezcla social e integración urbana: Aproximaciones teóricas y discusión del caso chileno. Revista INVI, 34(95), 45-69. http://dx.doi.org/10.4067/S0718-83582019000100045

Sabatini, F., Cáceres, G., \& Cerda, J. (2001). Segregación residencial en las principales ciudades chilenas: Tendencias de las tres últimas décadas y posibles cursos de acción. Revista EURE - Revista de Estudios Urbano Regionales, 27(82). Recuperado de http:// www.eure.cl/index.php/eure/article/view/1258

Sabatini, F., Rasse, A., Mora, P., \& Brain, I. (2012). ¿Es posible la integración residencial en las ciudades chilenas?: Disposición de los grupos medios y altos a la integración con grupos de extracción popular. EURE (Santiago), 38(115), 159-194. https://doi. org/10.4067/S0250-71612012000300008

Sabatini, F., \& Sierralta, C. (2006). Medición de la Segregación Residencial: Meandros Teóricos y Metodológicos, y Especificidad Latinoamericana. Documento de Trabajo, 38.

Sabatini, F., \& Vergara, L. (2018). ¿Apoyo a lugares o apoyo a personas? Dos proyectos chilenos de vivienda socialmente integrada. Revista INVI, 33(94), 9-48. http://dx.doi.org/10.4067/S0718-83582018000300009
Slater, T. (2013). Your Life Chances Affect Where You Live: A Critique of the 'Cottage Industry' of Neighbourhood Effects Research. International Journal of Urban and Regional Research, 37(2),367387. https://doi.org/10.1111/j.1468-2427.2013.01215.x

Theoduloz, I. (2016). Vivienda social en el centro de santiago - neo-cité san francisco. Revista ciudad $y$ arquitectura, 152(05), 1. Recuperado de http:// revistaca.cl/portada-revista-ca-152/dossier-de-obrasportada/dossier03-emprendimiento-de-arquitecturasocial-por-una-ciudad-inclusiva-y-sustentable/

Tironi, M. (2004). El lugar de la pobreza. Características, cambios y escalas. Centro de Investigación Social (CIS), 4, 22-29.

Vergara-Erices, L., \& Garín Contreras, A. (2016). Vivienda social y segregación socioespacial en una ciudad pequeña: El caso de Angol, Chile. Polis (Santiago), 15(44), 457-486. https://doi.org/10.4067/ S0718-65682016000200021

Villamizar, S. (2015). Desigualdades sociales, ¿inequidades espaciales? Análisis de la segregación sociorracial en Bogotá (2005-2011). Revista Colombiana de Sociología, 38(2). Recuperado de https://revistas.unal.edu.co/index.php/recs/article/ view/54901

Wacquant, L. (2000). Las cárceles de la miseria. Buenos Aires: Manantial. 